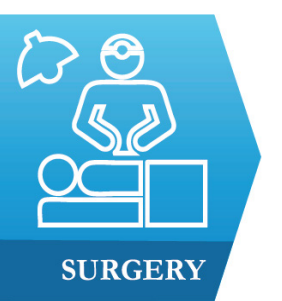

Hôpitaux Civils de Colmar, Médecine A, France

DOI: $10.15386 / \mathrm{mpr}-1429$

Manuscript received: 24.07 .2019

Received in revised form: 25.09.2019

Accepted: 22.01.2020

Address for correspondence:

marcel.gheorghiu1@yahoo.com

This work is licensed under a Creative Commons Attribution-NonCommercialNoDerivatives 4.0 International License

\section{Case report of abdominal left upper quadrant collection secondary to fish bone perforation}

Marcel Ioan Gheorghiu, Marion Bolliet, Patrice David, Bernard Denis

\begin{abstract}
We present an unusual case of an intra-abdominal collection which evidenced a rare etiology and raises diagnostic particularities.

Background. Fish bones ingestion is frequent, but seldom followed by complications. Those are often reported at specific sites.

Objectives. This case report emphasizes the unusual presentation and site localization of a colonic perforation by a small fish bone, in the context of limited radiological accuracy at the diagnostic phase.

Case presentation. A 37 year old male was admitted to the gastroenterology ward with upper and left sided abdominal pain associated with fever and marked fatigue. His medical history was marked by a sleeve gastrectomy in 2010 for obesity. Abdominal signs and elevated acute inflammatory syndrome on blood tests were followed by computer tomography which revealed a pericolic mass near the left splenic flexure. The pain and fever increased in intensity, so a laparotomy was proposed. Intraoperatively, a tumor-like lesion was found and a resection with oncologic limits was performed. Microscopic examination of the specimen revealed a fish bone, but only after surgery did the patient confirm that he had eaten fish meal the week before. The post-operative period was uneventful.

Conclusion. Fish bones remain some of the most frequently ingested alimentary foreign bodies; they may cause atypical clinical presentations, frequently omitted by the patients themselves if symptoms appear delayed. They could also lead to possible high-risk complications which need to be addressed by surgeons.
\end{abstract}

Keywords: left colic, collection, cancer, fish bone, foreign bodies

\section{Background}

Statistically foreign body ingestion is more frequent with prison inmates, in patients with psychotic disorders, at extreme ages (children, denture-wearing elderly) and with alcoholics. Most foreign bodies may pass spontaneously through the digestive tract; some of them may need endoscopic extraction while surgery is seldom needed [1,2]. Fish bones are the most frequently ingested organic foreign objects, but complications such as mechanical obstruction or small bowel perforation are rare [2-6].

Fish bones are small pointed objects; through their passage, complications such as obstruction or perforation are anticipated in the regions of the angulations of the digestive tract. They remain a difficult clinical diagnosis because of difficulties in image identification and characterization $[1,4,7]$. Usual sites for colonic perforation are the caecum and the sigmoid, whereas a few cases may be reported at other locations.

We report herewith the case of a pericolic abscess as a complication of a fish bone perforation of the left colic flexure.

\section{Case presentation}

A 37 year old male was admitted to the gastroenterology ward of a district hospital with upper-left abdominal pain for the past 3 days associated with fever and marked fatigue. 
His relevant medical history was only a sleeve gastrectomy in 2010, which he had underwent without significant complications. He reported no toxicological addictions and no local abdominal trauma.

At the time of the examination, the patient had fever $39^{\circ} \mathrm{C}$, and he had abdominal left upper quadrant tenderness, but without guarding.

Admission blood tests were marked by an important inflammatory syndrome $(\mathrm{C}$ reactive protein - CRP over $300 \mathrm{mg} / \mathrm{L}$, leucocytes $12.750 / \mathrm{mm}^{3}$ ); the rest of the blood tests were within normal range. An emergency computer tomography (CT) with contrast noted a left flexure pericolic mass of $70 \mathrm{~mm}$ in the largest diameter, with contrast-enhanced walls and heterogenic content, with suspicion over invasiveness of the neighboring pancreatic fatty tissue and spleen. No clear etiology was apparent at the time of admission, neither the exclusion of abdominal malignancy was possible with certainty (Figures 1-4). Colonoscopy was dismissed because of the suspicion of colic perforation and localized peritonitis.

\section{Differential diagnosis}

Several entities were considered within the differential diagnosis, including: carcinoma of the colon or tail of the pancreas, an abdominal sarcoma, perforation related to diverticulitis or a foreign body.
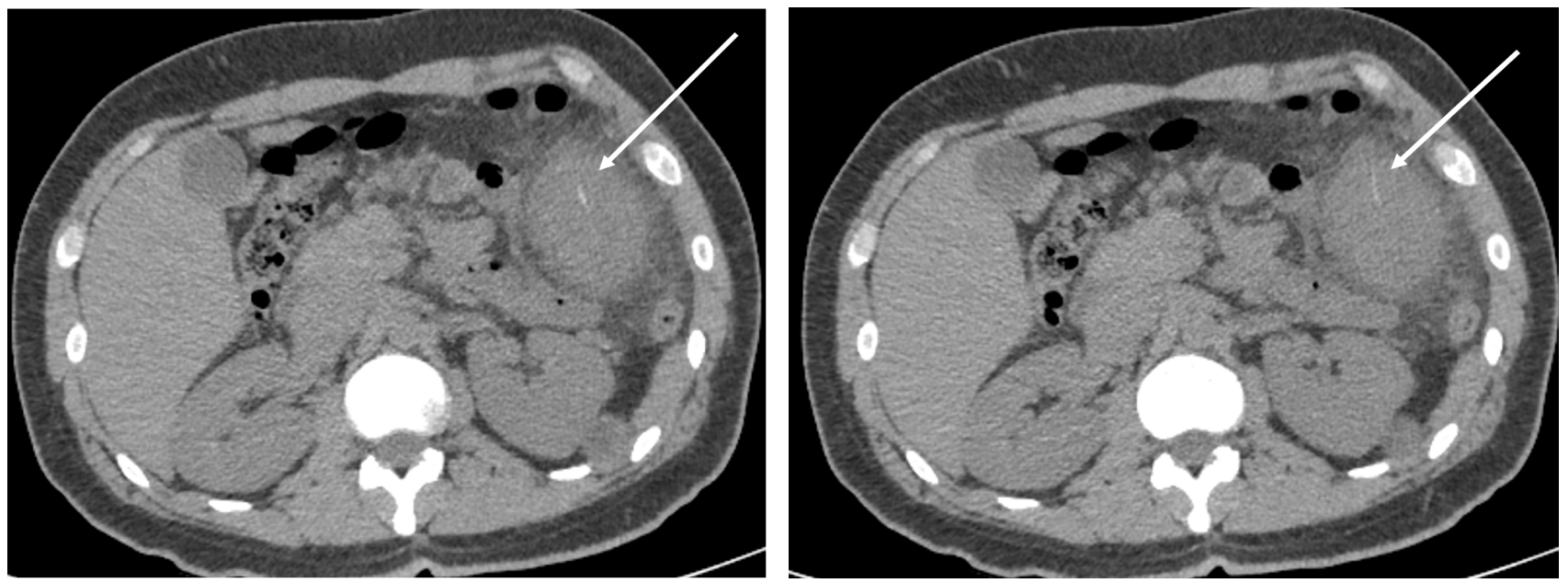

Figures 1 and 2. Native abdominal computer tomography, infra-splenic level: a mass with heterogenous density and apparent wall situated between the splenic flexure and the spleen; with a hyperdense linear object inside, but cannot be followed in the colic lumen; no signs of pneumoperitoneum.
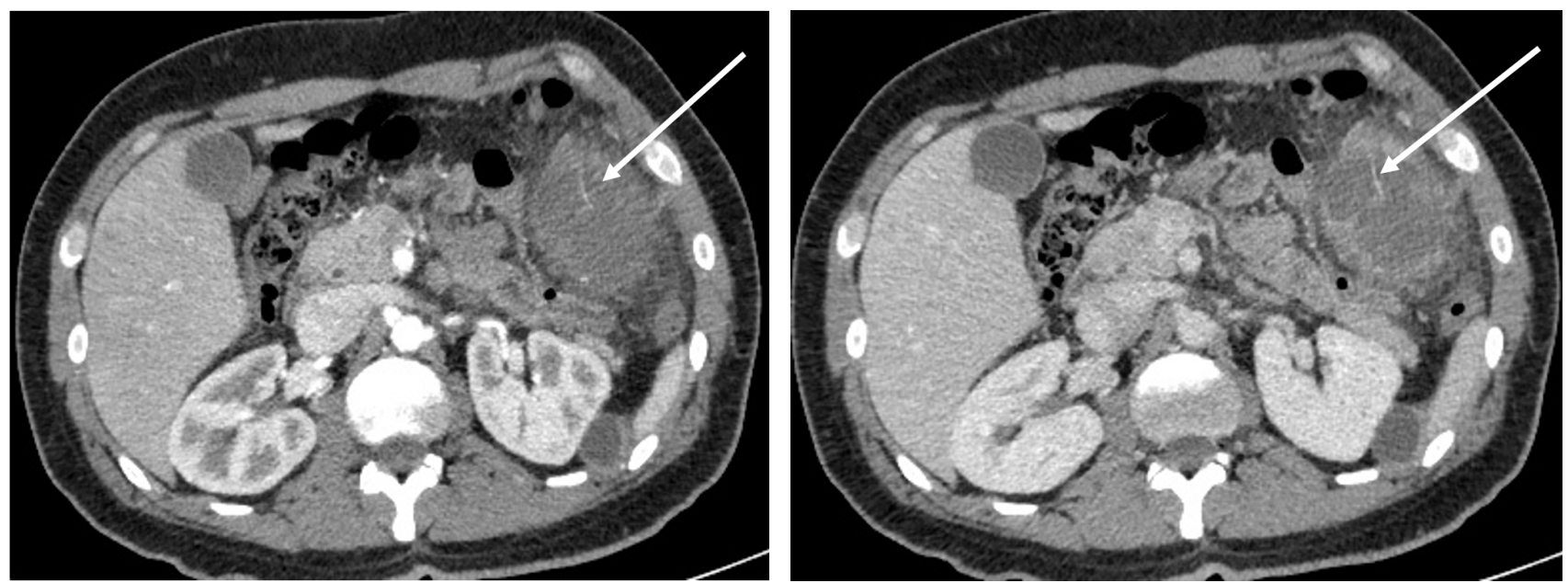

Figures 3 and 4. Contrast-enhanced computer tomography, arterial (Figure 3) and portal phase (Figure 4): mass belonging to colonic wall, heterogenic content, contrast enhanced walls; non-specific aspect, malignancy cannot be excluded; Figures emphasize the contrast enhancement, with suspicion of septae or mural nodules, also the extracolic location of the fish bone seen only in multiple sequences. 


\section{Treatment}

We started empiric antibiotics with Amoxicillinclavulanic acid and escalated to PiperacillinTazobactam associated with Metronidazole based on the nonresponsive inflammatory syndrome.

A review of the case with our surgeons proposed an exploratory laparotomy. After a left subcostal (Kocher) incision, the mass was identified as belonging to the left colic flexure and the meso-colic fascia; the tumor was also adherent/invasive to the spleen. After dissection, the tumor and the left colic flexure were removed in block for histological examination, followed by the end-to-end anastomosis of the remaining colon.

\section{Outcome and follow-up}

Macroscopic examination of the specimen found a perforating fish bone. The microscopic analysis of the specimen retained the same diagnostic, confirming the secondary abscess and it excluded any malignant component of the removed mass and colon.

The drains were progressively removed between day 5 and day 10 post-surgery and surgical wound progress was favorable. Post-operatively, the patient developed a left-sided pneumonia, despite ongoing antibiotic treatment, and he was escalated to Linezolid. The patient was discharged day 10 post-surgery, with the residual pain controlled by level 1 analgesia, a clean surgical wound and normal bowel movement.

During the following month, the patient was readmitted for sub-obstructive symptoms which were mitigated by medical treatment. Follow-up at 3 months was normal.

\section{Discussion}

Ingested fish bones are frequently asymptomatic, and they are discarded by the digestive tract. Usually they become impacted in zones of angles of the digestive tract or sphincters such as the pharynx, esophagus, pylorus, duodenum where most of them can be managed endoscopically, or in the colon at the ileo-caecal valve or the sigmoid. The delay in passing the cardia and the duodenum makes correlation with later symptoms difficult, because patients usually do not remember the time of ingestion. In contrast to a gastro-duodenal perforation by a foreign body complicated with chemical peritonitis that is quite symptomatic, a colon perforation may evolve with a sub-acute clinical peritonitis and/or abscess formation; this may mean milder symptoms; adding a significant delay from the intake of the foreign body, the presentation leaves the differential diagnosis open for debate at admission time between emergency room (ER), radiology and surgeons [1,3-6]. A case series report about ingested radio-opaque foreign bodies describes a mean time for spontaneous passage through the digestive tract of less than 1 week in $75 \%$ of cases, with a mean hospital stay of 3.4 days. The same group describes endoscopic intervention in $20 \%$ of the remaining cases [1].

Plain radiography is limited in detecting fish bones $[4,7,8]$. Despite the superiority of the CT versus radiography, one author notes a sensitivity of only $70 \%$ related to fish bone perforation due to: radiologist awareness and super-imposing other structures such as blood vessels; initial reports improved on retrospective reviews of images (review case images: Figures 1-4). In most case reports, the radiologist described the complications, but their etiology remained vague $[9,10]$. The same author underlines the risk of masking the fish bone by oral contrast agents [9]. This is in contrast to chicken bones; because of their size and radiologic characteristics they are readily diagnosed. $[1,6,7,9]$. There are debates about the use of ultrasound in select cases for finding the foreign object in an abdominal mass [11].

The management of the ingested foreign bodies depends on their impaction, location, shape, length and corrosive risk. Most objects impacted in the upper digestive tract (including pharynx) are very symptomatic but can be managed by upper digestive endoscopy or direct pharyngo-laryngeal approach. For objects that have passed the duodenum, surveillance is proposed with some exceptions such as magnets and batteries [12]. Endoscopy may be attempted in objects impacted at the level of the recto-sigmoid region. Different techniques are described, but retrieval with a polypectomy snare is often the case $[12,13]$. In the acute settings, surgery with extraction of the foreign body is proposed for acute complications such as peritonitis, hemorrhage control or drainage of abscesses $[1,2,14,15]$. Surgery is also recommended in cases of sharp-pointed objects that cannot be retrieved by endoscopy and intestinal impaction suggested by lack of progression for 72 hours on X-Ray $[7,12]$. Selected cases can be successfully treated by percutaneous abscess drainage or with antibiotics therapy alone $[16,17]$. In cases of long standing inflammation, a preliminary antibiotic therapy could reduce the local inflammation, thus facilitating surgical debridement and extraction $[2,4,8,16,17]$. The most important is to remove any suspicion of digestive tumor or inflammatory bower disease $[6,15,18,19]$.

In this case, the initial supposition was an intraabdominal abscess of unknown etiology that did not respond favorably to medical treatment. Local complication following the sleeve gastrectomy the patient had some 10 years beforehand was highly improbable because of the asymptomatic time span between the two. No other infection site was found, so the cause for the associated progressive sepsis was associated with the perforation of the colon. In the possible context of a malignant mass, foreign body or diverticulitis, surgery was prioritized. Because we could not exclude a malignant tumor of the colon or of the tail of the pancreas, the surgeons opted for an oncological approach of the mass, as recommended 
$[15,19]$. Retrospectively, the patient recalled eating fish the week before; the review of the images confirmed the fish bone fine appearance that could be mistaken for a blood vessel in contrast CT imaging.

We could not perform the coloscopy to eliminate a colonic malignant process as a standard procedure in other case reports $[6,20]$. The patient had no personal or family risk factors for colorectal cancer and the progressive sepsis raised the suspicion of possible colon perforation with peritonitis that contraindicated the preparation and the colonoscopy.

We found one other case report of splenic flexure perforation by a wooden toothpick that was managed endoscopically by snare-extraction because part of the toothpick was still inside the colonic lumen. The postendoscopy micro-perforation and pneumo-peritoneum were successfully treated conservatively with antibiotics [20]. A similar case to ours describes the extra-colonic migration of a fish bone to the spleen complicated with a hematoma and indication of surgical intervention [21]. Another group of authors describe a similar approach to ours in a pediatric patient [22].

The case report was written following CARE guidelines [23].

\section{Conclusion}

In conclusion, fish bones remain the most frequent ingested (dietary) foreign body; they may cause atypical ER presentations, frequently omitted by patients if there are delayed symptoms, and they could lead to possible high-risk complications which need to be addressed by surgeons.

\section{Learning points}

This case highlights the differential diagnosis of a pericolic abscess, while clinical progression dictates the diagnostic and therapeutic approach.

Ingestion of a foreign body has a variety of modes of presentation, including acute or an insidious onset, as well as symptomatic complications; however, most of the foreign bodies pass the digestive tract asymptomatically.

Management of the complications of ingestion of a foreign body should be guided by a clinical setting and radiological imaging and can include both open and/or intraluminal techniques.

\section{References}

1. Velitchkov NG, Grigorov GI, Losanoff JE, Kjossev KT. Ingested foreign bodies of the gastrointestinal tract: retrospective analysis of 542 cases. World J Surg. 1996;20:1001-1005.

2. Mesina C, Vasile I, Valcea DI, Pasalega M, Calota F, Paranescu H, et al. Problems of diagnosis and treatment caused by ingested foreign bodies. Chirurgia (Bucur).
2013;108:400-406.

3. Yamamoto M, Yamamoto K, Sasaki T, Fukumori D, Yamamoto F, Igimi $\mathrm{H}$, et al. Successfully treated intraabdominal abscess caused by fish bone with perforation of ascending colon: a case report. Int Surg. 2015;100:428-430.

4. de la Vega M, Rivero JC, Ruíz L, Suárez S. A fish bone in the liver. Lancet. 2001;358:982.

5. Puia IC, Puia VR, Andreescu A, Cristea PG. Ascending colon perforation by ingested fruit stones. Chirurgia (Bucur). 2011;106:825-827.

6. Wright J, Roy P, Linsell J. Be careful what you wish for: an ingested foreign body masquerading as cancer. BMJ Case Rep. 2010;2010:pii: bcr0520103024. doi: 10.1136/ bcr.05.2010.3024

7. Pinero Madrona A, Fernández Hernández JA, Carrasco Prats M, Riquelme Riquelme J, Parrila Paricio P. Intestinal perforation by foreign bodies. Eur J Surg. 2000;166:307309.

8. Mutlu A, Uysal E, Ulusoy L, Duran C, Selamoğlu D. A fish bone causing ileal perforationin the terminal ileum. Ulus Travma Acil Cerrahi Derg. 2012;18:89-91.

9. Goh BK, Tan YM, Lin SE, Chow PK, Cheah FK, Ooi LL, et al. CT in the preoperative diagnosis of fish bone perforation of the gastrointestinal tract. AJR Am J Roentgenol. 2006;187:710-714.

10. Takada M, Kashiwagi R, Sakane M, Tabata F, Kuroda Y. 3DCT diagnosis for ingested foreign bodies. Am J Emerg Med. 2000;18:192-193.

11. Hu JH, Yao WY, Jin QH. A Rare Case of Ascending Colon Perforation Caused by a Large Fish Bone. Chin Med J (Engl). 2017;130:377-378.

12. Birk $M$, Bauerfeind $P$, Deprez $P$, Häfner $M$, Hartmann $\mathrm{D}$, Hassan C, et al. Removal of foreign bodies in the upper gastrointestinal tract in adults: European Society of Gastrointestinal Endoscopy (ESGE) Clinical Guideline. Endoscopy. 2016;48:489-496.

13. Fang C, Ye L, Mao X, Zhang J. Endoscopic treatment of a sigmoid perforation caused by an ingested fish bone. Endoscopy. 2017;49(S 01):E82-E83.

14. Yang Z, Wu D, Xiong D, Li Y. Gastrointestinal perforation secondary to accidental ingestion of toothpicks: A series case report. Medicine (Baltimore). 2017;96:e9066.

15. McGregor DH, Liu X, Ulusarac O, Ponnuru KD, Schnepp SL. Colonic perforation resulting from ingested chicken bone revealing previously undiagnosed colonic adenocarcinoma: report of a case and review of literature. World J Surg Oncol. 2011;9:24.

16. Ng CT, Htoo A, Tan SY. Fish bone-induced hepatic abscess: medical treatment. Singapore Med J. 2011;52:e56-e58.

17. Ward MA, Tews MC. Small bowel perforation secondary to fish bone ingestion managed non-operatively. J Emerg Med. 2012;43:e295-e298.

18. Rodrigues FG, Campos JB, Silva GD, Wexner SD. Endoscopic ultrasound in the diagnosis of foreign bodies of the colon and rectum. Rev Assoc Med Bras (1992). 2016;62:818-821. 
19. Terrace JD, Samuel J, Robertson JH, Wilson RG, Anderson DN. Chicken or the leg: Sigmoid colon perforation by ingested poultry fibula proximal to an occult malignancy. Int J Surg Case Rep. 2013;4:945-947.

20. Sarici IS, Topuz O, Sevim Y, Sarigoz T, Ertan T, Karabıyık $\mathrm{O}$, et al. Endoscopic Management of Colonic Perforation due to Ingestion of a Wooden Toothpick. Am J Case Rep. 2017;18:72-75.

21. Sierra-Ruiz M, Sáenz-Copete JC, Enriquez-Marulanda A,
Ordoñez CA. Extra luminal migration of ingested fish bone to the spleen as an unusual cause of splenic rupture: Case report and literature review. Int J Surg Case Rep. 2016;25:184-187.

22. Azahouani A, Hida M, Benhaddou H. Inflammatory tumor of the great omentum after ingestion of a bone fragment. Arch Pediatr. 2016;23:180-183.

23. Gagnier JJ, Kienle G, Altman DG, Moher D, Sox H, Riley D, et al. The CARE guidelines: consensus-based clinical case report guideline development. J Clin Epidemiol. 2014;67:46-51. 